TITLE:

\title{
Annulative Synthesis of Thiazoles and Oxazoles from Alkenyl Sulfoxides and Nitriles via Additive Pummerer Reaction
}

\section{AUTHOR(S):}

Hori, Mitsuki; Nogi, Keisuke; Nagaki, Aiichiro;

Yorimitsu, Hideki

\section{CITATION:}

Hori, Mitsuki ... [et al]. Annulative Synthesis of Thiazoles and Oxazoles from Alkenyl Sulfoxides and Nitriles via Additive Pummerer Reaction. Asian Journal of Organic Chemistry 2019, 8(7): 1084-1087

\section{ISSUE DATE:}

2019-07

URL:

http://hdl.handle.net/2433/243226

\section{RIGHT:}

This is the peer reviewed version of the following article: M. Hori, K. Nogi, A. Nagaki, H. Yorimitsu, Asian J. Org. Chem. 2019, 8, 1084., which has been published in final form at https://doi.org/10.1002/ajoc.201900169. This article may be used for non-commercial purposes in accordance with Wiley Terms and Conditions for Use of Self-Archived Versions.; The full-text file will be made open to the public on 22 July 2020 in accordance with publisher's 'Terms and Conditions for Self-Archiving'.: This is not the published version. Please cite only the published version.: この論文は出版社版であり ません。引用の際には出版社版をご確認ご利用ください。 


\title{
Annulative Synthesis of Thiazoles and Oxazoles from Alkenyl Sulfoxides and Nitriles via Additive Pummerer Reaction
}

\author{
Mitsuki Hori, Keisuke Nogi, Aiichiro Nagaki, and Hideki Yorimitsu*
}

\begin{abstract}
Pummerer-based annulation of alkenyl sulfoxides, mainly ketene dithioacetal monoxides (KDMs), with nitriles has been developed. By means of trifluoromethanesulfonic anhydride $\left(\mathrm{Tf}_{2} \mathrm{O}\right)$ as an activator, additive Pummerer reaction and subsequent $\mathrm{C}-\mathrm{S}$-bondforming cyclization from the nitrilium intermediates furnished the corresponding thiazoles. Moreover, the nitrilium intermediates proved to be interrupted intermolecularly by $\mathrm{H}_{2} \mathrm{O}$ to afford oxazoles instead of thiazoles.
\end{abstract}

The Pummerer reaction is a unique transformation of sulfoxides, and has been recognized as a powerful and attractive method in organic synthesis. ${ }^{[1]}$ Besides classical Pummerer reactions of alkyl sulfoxides, transformations of aryl and alkenyl sulfoxides, called extended Pummerer reactions, have been actively investigated over the last two decades. ${ }^{[2]}$

Recently, we have been interested in Pummerer-based transformations of alkenyl sulfoxides including ketene dithioacetal monoxides (KDMs). ${ }^{[2 e, h, 3]}$ To develop new Pummerer-based transformation of KDMs, we conducted the reaction of KDM 1a with a series of nucleophiles. During the course of the investigation, we accidentally found that 5(methylsulfanyl)thiazole 3aa was obtained when $\mathbf{1 a}$ and trifluoromethanesulfonic anhydride $\left(\mathrm{Tf}_{2} \mathrm{O}\right)$ were mixed in acetonitrile (2a) as a solvent (Scheme 1). The reaction would be initiated by activation of KDM $1 \mathrm{a}$ with $\mathrm{Tf}_{2} \mathrm{O}$ to generate sulfonium A. Subsequent additive Pummerer-type reaction, ${ }^{[2 a-d]}$ in which the nitrogen atom of acetonitrile undergoes $S_{N} 2$-type reaction, would afford intermediate B. Following C-S-bond-forming cyclization, and deprotonation would afford $S$-methylthiazolium D. Finally, demethylation of $\mathbf{D}$ would provide thiazole $3 \mathbf{a a} .{ }^{[4]}$

The reaction of nitriles under Pummerer conditions was first reported by Vanker. ${ }^{[5]}$ In that report, Ritter-type addition of nitriles to the a-position of alkyl sulfoxides took place and subsequent hydrolysis afforded $\alpha$-amidoalkyl sulfides as products. Very recently, Peng reported the reactions of aryl sulfoxides with alkanenitriles under Pummerer conditions. ${ }^{[6]}$ In these cases, interrupted Pummerer reaction proceeded, in which the nitrogen

[a] M. Hori, Dr. K. Nogi, Prof. Dr. H. Yorimitsu Department of Chemistry, Graduate School of Science, Kyoto University, Sakyo-ku, Kyoto 606-8502 (Japan) E-mail: yori@kuchem.kyoto-u.ac.jp

[b] Prof. Dr. A. Nagaki

Department of Synthetic Chemistry and Biological Chemistry, Graduate School of Engineering,

Kyoto University, Nishikyo-ku, Kyoto 615-8510 (Japan)

E-mail: anagaki@sbchem.kyoto-u.ac.jp

Supporting information for this article is given via a link at the end of the document. atom attacked onto the sulfur atom to construct an $\mathrm{S}-\mathrm{N}$ bond, instead of additive Pummerer reaction. The following $[3,3]$ sigmatropic rearrangement produced ortho-cyanoalkylation products. To the best of our knowledge, additive Pummerer reaction with nitriles has never been reported.

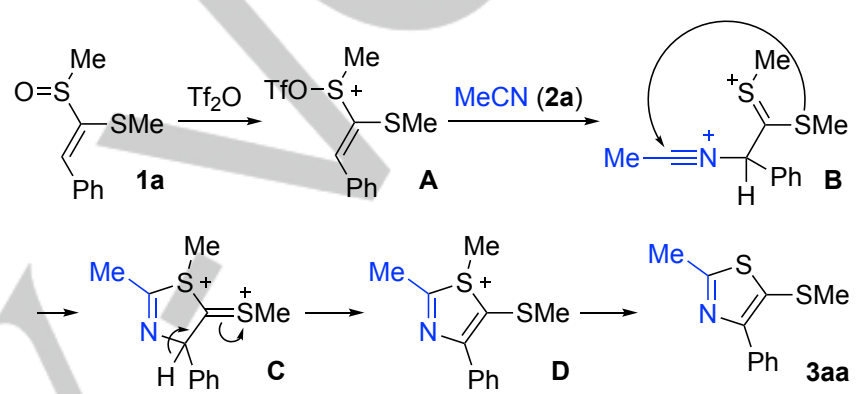

Scheme 1. Possible reaction mechanism for formation of thiazole 3aa.

Thiazoles represent an important structural motif in various functional molecules including biologically active compounds ${ }^{[7]}$ and functional materials. ${ }^{[8]}$ Although a number of methodologies for the synthesis of thiazoles have been established, ${ }^{[9,10]}$ we expected that the development of a new route to thiazoles from readily accessible alkenyl sulfoxides and nitriles would be valuable. With these considerations in mind, here we report annulative synthesis of thiazoles via additive Pummerer reaction of alkenyl sulfoxides with alkane- and arenenitriles. Moreover, we found that interception of nitrilium intermediate of the type B by $\mathrm{H}_{2} \mathrm{O}$ intermolecularly provided the corresponding oxazoles instead of thiazoles.

Optimization study for the synthesis of 3 aa is summarized in Table 1. The reaction of $1 \mathrm{a}$ with 192 equivalents of acetonitrile in the presence of 1.0 equivalent of $\mathrm{Tf}_{2} \mathrm{O}$ afforded a $53 \%$ yield of $\mathbf{3 a a}$ (entry 1). Increasing the concentration of $1 \mathrm{a}$ as high as $0.2 \mathrm{M}$ improved the yield of $3 \mathrm{aa}$ to $62 \%$ while the higher concentration of 1a $(0.4 \mathrm{M})$ slightly decreased the yield (entries 2 and 3). Although a $58 \%$ yield of 3 aa was obtained when the reaction was conducted with 48 equivalents of $\mathbf{2 a}$ using $\mathrm{MeNO}_{2}$ as a co-solvent, the use of 10 equivalents of $2 a$ significantly diminished the yield of 3 aa to $28 \%$ (entries 4 and 5). By means of 1.5 equivalents of $\mathrm{Tf}_{2} \mathrm{O}$ and 96 equivalents of acetonitrile as a single solvent, 3aa was obtained in $77 \%$ yield and was isolated in $75 \%$ yield (entry 6 ). 
Table 1. Condition screenings.

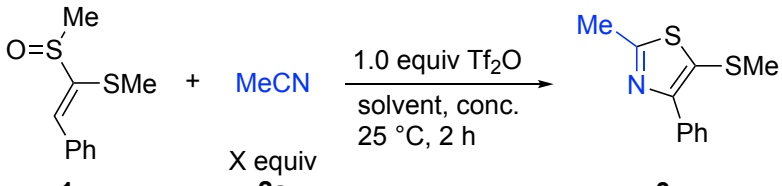

$$
\begin{aligned}
& \text { 1a 2a 3aa }
\end{aligned}
$$

\begin{tabular}{lllll}
\hline entry & X (equiv) & solvent & conc. (M) & NMR yield (\%) \\
\hline 1 & 192 & neat & 0.1 & 53 \\
2 & 96 & neat & 0.2 & 62 \\
3 & 48 & neat & 0.4 & 56 \\
4 & 48 & MeNO $_{2}$ & 0.2 & 58 \\
5 & 10 & MeNO $_{2}$ & 0.2 & 28 \\
$6^{[a]}$ & 96 & neat & 0.2 & $77(75)^{[b]}$ \\
\hline
\end{tabular}

[a] 1.5 equiv of $\mathrm{Tf}_{2} \mathrm{O}$. [b] Isolated yield.

The scope of the reaction with respect to KDMs is shown in Scheme 2. KDMs having electronically neutral aryl rings at the $\beta$ position were applicable to the reaction to afford thiazoles $\mathbf{3 b a}$ 3fa in moderate yields. On the other hand, considerably electrondonating and -withdrawing 4-methoxphenyl and 4-nitrophenyl groups proved to be not suitable. The desired products, $\mathbf{3 g a}$ and 3ha, were obtained in less than $10 \%$ yields while the KDMs were completely consumed. $\beta$-Alkyl substituted KDMs, $\mathbf{1} \mathbf{i}$ and $\mathbf{1} \mathbf{j}$, gave complex product mixtures. The sulfanyl moiety at the $\alpha$-position was crucial for the reaction, and $\alpha$-phenyl and $\alpha$-unsubstituted alkenyl sulfoxides $\mathbf{1 k}$ and $\mathbf{1 l}$ also afforded complex product mixtures.

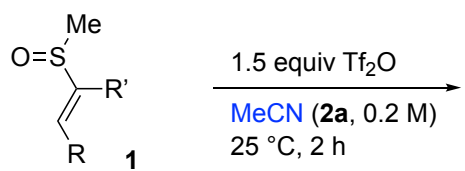
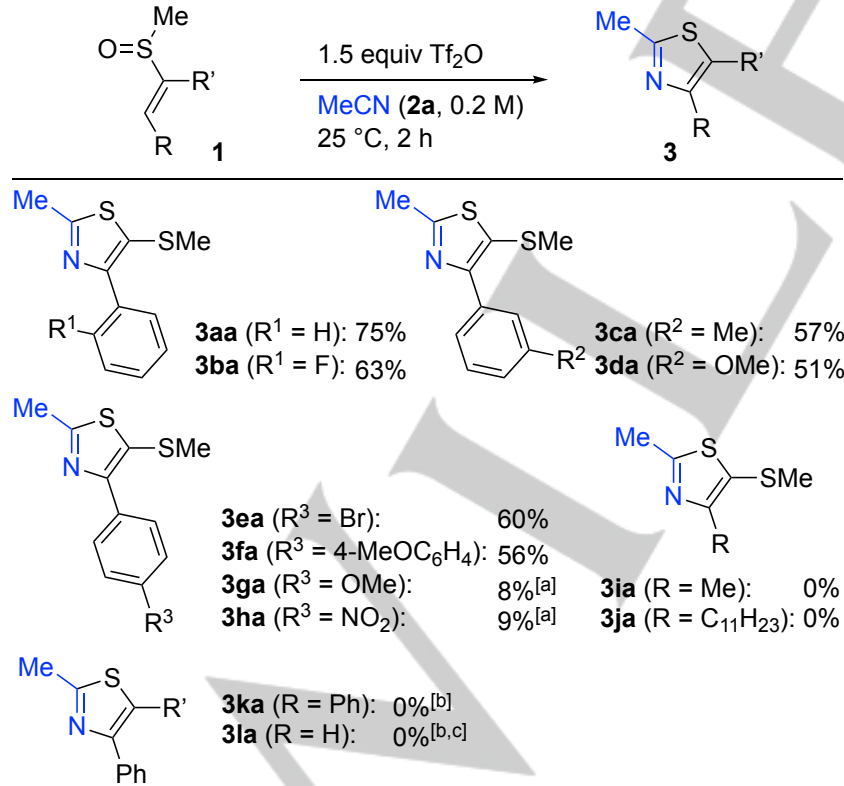

3ka $(\mathrm{R}=\mathrm{Ph}): 0 \%[\mathrm{~b}]$ 3la $(\mathrm{R}=\mathrm{H}): \quad 0 \%[\mathrm{~b}, \mathrm{c}$

Scheme 2. Scope of KDMs. [a] NMR yield. [b] At $0{ }^{\circ} \mathrm{C}$. [c] Dodecyl 2-phenylvinyl sulfoxide (11) was used.

Next, we investigated the scope with respect to nitriles (Scheme 3). Instead of $\mathbf{2 a}$, butyronitrile (2b) also participated in the reaction.

In this case, the use of $\mathrm{MeNO}_{2}$ as a co-solvent slightly improved the yield of $3 \mathbf{a b}$ to $64 \%$. Therefore, we decided to use the cosolvent system $\left(\mathrm{MeNO}_{2} /\right.$ nitrile $\left.2=1 / 1, \mathrm{v} / \mathrm{v}\right)$ for exploring the scope with respect to nitriles. As a secondary alkanenitrile, isobutyronitrile (2c) was converted to the corresponding thiazole 3 ac in $60 \%$ yield. The use of 4 -chlorobutyronitrile (2d) also afforded the desired product $3 \mathrm{ad}$ in $48 \%$ yield. Phenylacetonitrile (2e) smoothly underwent the present transformation affording benzyl-substituted thiazole $3 a e$ in a moderate yield. Fortunately, arenenitriles were also found to be applicable. The reaction of $\mathbf{1 a}$ with benzonitrile (2f) furnished the corresponding thiazole 3 af in $64 \%$ yield. Electron-rich 4-methoxybenzonitrile (2g) promptly reacted with $1 \mathrm{a}$ to afford $\mathbf{3 a g}$ in $64 \%$ yield even though the amount of $\mathbf{2 g}$ was reduced to 3.0 equivalents. Although the employment of 2-methoxybenzonitrile resulted in a low yield of the product probably due to its steric hindrance, sterically less hindered 2fluorobenzonitrile $(\mathbf{2 h})$ was involved in the reaction to afford $3 \mathbf{a h}$ in $55 \%$ yield. Gratifyingly, the reaction of acrylonitrile (2i) and trans-crotononitrile (2j) furnished desired products 3ai and 3aj in moderate yields without deterioration of their $\mathrm{C}-\mathrm{C}$ double bonds.

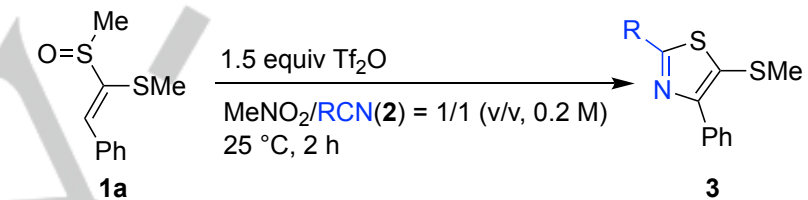

Pr

3ab: $60 \%[a, b]$ 3ab: $64 \%$<smiles>COc1sc(Cc2ccccc2)nc1-c1ccccc1</smiles>

3ae: $51 \%$<smiles>Cc1sc(C(C)C)nc1-c1ccccc1</smiles>

3ac: $60 \%$<smiles>[R]c1ccccc1-c1nc(-c2ccccc2)c(S(C)(=O)=O)s1</smiles><smiles>Cc1sc(CCCCl)nc1-c1ccccc1</smiles>

3ad: $48 \%$<smiles>[R]C=Cc1nc(-c2ccccc2)c(C)s1</smiles>

$$
\begin{aligned}
& \text { 3af }(R=H): \quad 64 \% \quad \text { 3ai }(R=H): \quad 59 \% \\
& \text { 3ag }(\mathrm{R}=4-\mathrm{OMe}): 64 \%[\mathrm{c}] \text { 3aj }(\mathrm{R}=\mathrm{Me}): 53 \% \\
& \text { 3ah }(R=2-F): \quad 55 \%
\end{aligned}
$$

Scheme 3. Scope of nitriles. [a] Without $\mathrm{MeNO}_{2}$. $\mathbf{2 b}$ was used as a solvent. [b] NMR yield. [c] 3.0 equiv of $\mathbf{2 g}, 3.0$ equiv of $\mathrm{Tf}_{2} \mathrm{O}$, for $0.5 \mathrm{~h}$.

In view of the reaction mechanism of the thiazole synthesis, we conceived that the intermediate like $\mathbf{B}$ generated via additive Pummerer-type reaction could be led to the corresponding oxazoles by the addition of water as an oxygen source (Scheme 4). We expected that nucleophilic attack of $\mathrm{H}_{2} \mathrm{O}$ to nitrilium $\mathbf{B}$ would afford thionium species $\mathbf{E}$, and subsequent $\mathrm{C}-\mathrm{O}$-bondforming cyclization and departure of methanethiol from $\mathbf{F}$ would provide oxazoles 4. Actually, in most reactions in Scheme 3, 5(methylsulfanyl)oxazoles were observed in around $5 \%$ yields because of a trace amount of water present in the reaction mixture. These observations encouraged us to explore the synthesis of oxazole. 


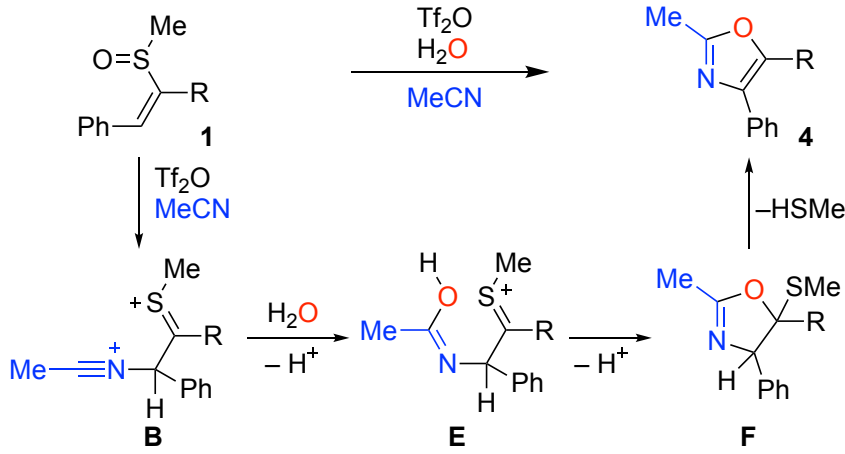

Scheme 4. Synthesis of oxazoles from alkenyl sulfoxides.

We first tired the reaction of $\operatorname{KDM~1a}$ with acetonitrile in the presence of $\mathrm{Tf}_{2} \mathrm{O}$ and 1.0 equivalent of $\mathrm{H}_{2} \mathrm{O}$. However, thiazole 3aa was still preferentially obtained and the yield of oxazole 4aa was only $3 \%$ (Scheme 5 ).

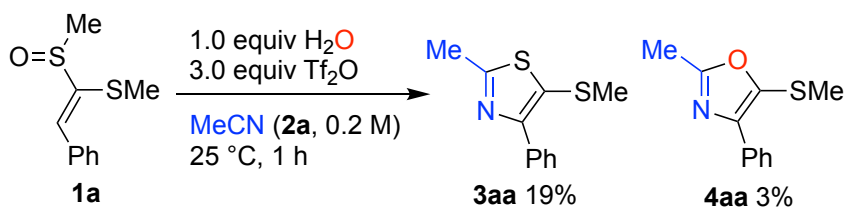

Scheme 5. Attempted synthesis of oxazole from KDM 1a. substituted alkenyl sulfoxides $1 \mathrm{~m}$ and $1 \mathrm{n}$ underwent the reaction, a-unsubstituted alkenyl sulfoxide 1 I was not applicable to afford a complex mixture. A methyl substituent at the a-position also diminished the yield of oxazole 4oa. Compared to the synthesis of thiazole shown in Schemes 2 and 3, the reaction efficiency was low and nitriles should be used as the solvent. However, both of alkane- and arenenitriles furnished the corresponding oxazoles $\mathbf{4 k b}-\mathbf{4 k f}$ and $\mathbf{4 k h}$ in moderate yields.

Next, we attempted the synthesis of thiazoles 3 in a larger scale. However, the reaction with $1 \mathrm{mmol}$ of $1 \mathrm{a}$ afforded much less yield of 3 aa as low as $55 \%$ ( $75 \%$ yield with $0.2 \mathrm{mmol}$ of $1 \mathrm{a}$, Scheme 2 ). We inferred that the efficiency of mixing of the substrates and $\mathrm{Tf}_{2} \mathrm{O}$ would be problematic in scaled-up experiments in batch reactors. We thus turned our attention to the use of flow microreactors that enables extremely fast mixing by virtue of the short diffusion path. ${ }^{[11]}$ The setup to realize the synthesis of 3aa is shown in Figure 1, consisting of a T-shape micromixer (M1) and a microtube reactor (R1). Solutions of KDM 1a in acetonitrile (2a) and $\mathrm{Tf}_{2} \mathrm{O}$ in $\mathrm{CH}_{2} \mathrm{Cl}_{2}$ were mixed together in $\mathbf{M} \mathbf{1}$ and reacted in $\mathbf{R} \mathbf{1}$ for $2.0 \mathrm{~s}$. The resulting mixture was collected in a flask, allowed to stand at room temperature for $0.5 \mathrm{~h}$, and treated with alumina for neutralization. As a result, we successfully obtained $\mathbf{3 a a}$ in $71 \%$ yield from $3.0 \mathrm{mmol}$ of $\mathbf{1 a}$.

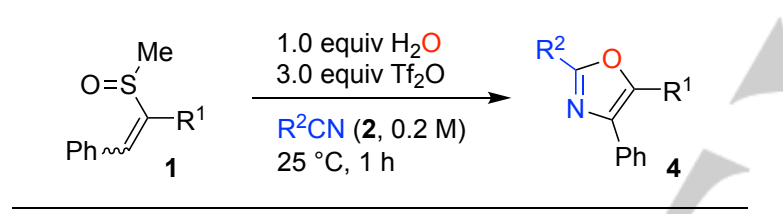<smiles>[R]c1ccc(-c2oc(C(C)C)nc2-c2ccccc2)cc1</smiles>

4ka $(\mathrm{R}=\mathrm{H}): \quad 46 \%$

$4 \mathrm{ma}(\mathrm{R}=t \mathrm{Bu}): 41 \%$

4na $(R=F): \quad 48 \%$

scope (nitriles)<smiles>CCCc1nc(-c2ccccc2)c(-c2ccccc2)o1</smiles>

4kb: $54 \%$<smiles>CC(C)c1nc(-c2ccccc2)c(-c2ccccc2)o1</smiles>

4kc: $56 \%$

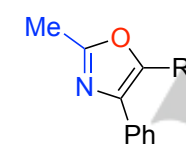

4la $(\mathrm{R}=\mathrm{H}): \quad 4 \%[\mathrm{a}, \mathrm{b}]$ 4oa $(\mathrm{R}=\mathrm{Me}): 27 \%[\mathrm{~b}]$<smiles>c1ccc(Cc2nc(-c3ccccc3)c(-c3ccccc3)o2)cc1</smiles><smiles>[R]c1ccccc1C#N</smiles>

4ke: $47 \%$

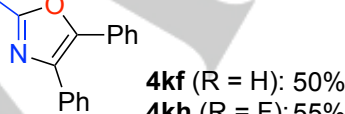

4kh $(R=F): 55 \%$

Scheme 6. Scope of the synthesis of oxazoles 4. [a] Dodecyl 2-phenylvinyl sulfoxide (11) was used. [b] NMR yield.

To suppress the $\mathbf{C}-\mathbf{S}$-bond formation (B to $\mathbf{C}$ in Scheme 1), $\mathbf{a}$ phenyl-substituted alkenyl sulfoxide $\mathbf{1 k}$ was used as a substrate. As a result, desired oxazole $\mathbf{4 k a}$ was obtained in $46 \%$ yield in the presence of 3.0 equivalents of $\mathrm{Tf}_{2} \mathrm{O}$ and 1.0 equivalent of $\mathrm{H}_{2} \mathrm{O}$ (Scheme 6). Although 4-tert-butylphenyl- and 4-fluorophenyl-

$\mathrm{O}=\mathrm{S}$

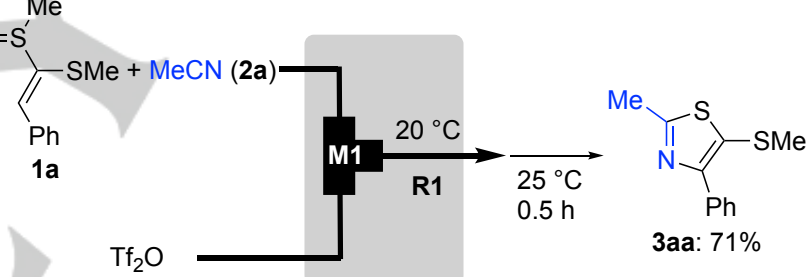

Flow conditions:

1a (0.1 M, 1.0 equiv), 2a (192 equiv as solvent);

$\mathrm{Tf}_{2} \mathrm{O}\left(0.1 \mathrm{M}\right.$ in $\mathrm{CH}_{2} \mathrm{Cl}_{2} 1.0$ equiv)

Figure 1. Large-scale synthesis in a flow microreactor.

To further demonstrate the utility of thiazoles 3 obtained, we subjected thiazole 3aa to transformations of the C-SMe bond. Hydrogenative removal of the methylsulfanyl moiety according to Nakada's protocol ${ }^{[12]}$ uneventfully proceeded to afford 2-methyl5 -phenyl-1,3-thiazole (5) in 85\% yield. (Scheme 7a). We then tried arylation of 3aa via $\mathrm{C}-\mathrm{S}$ bond cleavage. In the presence of 5 mol\% of Pd-PEPPSI-SIPr, Negishi-type arylation with an arylzinc reagent smoothly proceeded to afford the corresponding 5arylthiazole 6 in $90 \%$ yield (Scheme $7 \mathrm{~b}$ ). ${ }^{[13]}$ 
<smiles>Cc1nc(-c2ccccc2)c(C(C)(C)C)s1</smiles>

3aa<smiles>Cc1nc(-c2ccccc2)c(C(C)(C)C)s1</smiles>

3aa

$$
\begin{aligned}
& 3.0 \text { equiv } \mathrm{Et}_{3} \mathrm{SiH} \\
& 5 \mathrm{~mol}^{\circ} \mathrm{PdCl}_{2} \\
& \underset{\mathrm{THF}, 40}{ }{ }^{\circ} \mathrm{C}, 5 \mathrm{~h}
\end{aligned}
$$<smiles>Cc1nc(-c2ccccc2)c(C)s1</smiles>

5: $85 \%$$$
85 \%
$$

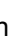

Scheme 7. Exocyclic C-S-cleaving transformations of thiazole $3 \mathbf{a a} . \mathrm{Ar}=4-$ $\mathrm{EtO}_{2} \mathrm{CC}_{6} \mathrm{H}_{4}$.

In conclusion, we have developed the annulative synthesis of 5(methylsulfanyl)thiazoles from KDMs and nitriles via additive Pummerer reaction. Moreover, the reaction pathway can be switched to the formation of oxazoles by adding $\mathrm{H}_{2} \mathrm{O}$ as the oxygen source.

\section{Acknowledgements}

This work was supported by JSPS KAKENHI Grant Numbers JP16H04109, JP18H04254, JP18H04409, and JP18K14212. H.Y. thanks The Mitsubishi Foundation for financial support.

Keywords: additive Pummerer reaction• Ritter-type reaction• alkenyl sulfoxide • thiazole $\cdot$ oxazole

[1] a) R. Pummerer, Chem. Ber. 1909, 42, 2282-2291; b) R. Pummerer Chem. Ber. 1910, 43, 1401-1412; c) T. Numata, S. Oae, J. Synth. Org. Chem., Jpn. 1977, 35, 726-738; d) D. S. Grierson, H. P. Husson, in Comprehensive Organic Synthesis, Vol. 6 (Eds.: B. M. Trost, I. Fleming), Pergamon Press, Oxford, 1991, 909-947; e) M. Kennedy, M. A. McKervey, in Comprehensive Organic Synthesis, Vol. 7 (Eds.: B. M. Trost, I. Fleming), Pergamon Press, Oxford, 1991, 193-216.

[2] Reviews: a) S. K. Bur, A. Padwa, Chem. Rev. 2004, 104, 2401-2432; b) K. S. Feldman, Tetrahedron 2006, 62, 5003-5034; c) S. Akai, Y. Kita, Top. Curr. Chem. 2007, 274, 35-76; d) L. H. S. Smith, S. C. Coote, H. F. Sneddon, D. J. Procter, Angew. Chem. Int. Ed. 2010, 49, 5832-5844; Angew. Chem. 2010, 49, 5968-5980; e) H. Yorimitsu, J. Synth. Org. Chem., Jpn. 2013, 71, 341-354; f) A. P. Pulis, D. J. Procter, Angew. Chem. Int. Ed. 2016, 55, 9842-9860; Angew. Chem. 2016, 128, 999610014; g) A. Shafir, Tetrahedron Lett. 2016, 57, 2673-2682; h) H. Yorimitsu, Chem. Rec. 2017, 17, 1156-1167; i) Z.-Y. Tian, Y.-H. Hu, H.B. Teng, C.-P. Zhang, Tetrahedron Lett. 2018, 59, 299-309; j) T. Yanagi, K. Nogi, H. Yorimitsu, Tetrahedron Lett. 2018, 59, 2951-2959.

[3] Recent examples: a) Y. Ookubo, A. Wakamiya, H. Yorimitsu, A. Osuka Chem. Eur. J. 2012, 18, 12690-12697; b) K. Murakami, H. Yorimitsu, A Osuka, Angew. Chem. Int. Ed. 2014, 53, 7510-7513; Angew. Chem. 2014, 126, 7640-7643; c) K. Murakami, H. Yorimitsu, A. Osuka, Bull. Chem. Soc. Jpn. 2014, 87, 1349-1366; d) K. Okamoto, M. Hori, T. Yanagi, K. Murakami, K. Nogi, H. Yorimitsu, Angew. Chem. Int. Ed. 2018, 57, 14230-14234; Angew. Chem. 2018, 130, 14426-14430; e) M. Hori, T. Yanagi, K. Murakami, H. Yorimitsu, Bull. Chem. Soc. Jpn. 2019, 92, 302-311.

[4] An excess amount of acetonitrile can work as the nucleophile for the demethylation. Indeed, when the reaction was conducted in $\mathrm{CD}_{3} \mathrm{CN}$ and monitored by ${ }^{1} \mathrm{H}$ NMR, neither of the $S$-methyl- or $N$-methylthiazolium was observed.

[5] Y. D. Vanker, C. T. Rao, Tetrahedron 1985, 41, 3405-3410.
[6] a) L. Shang, Y. Chang, F. Luo, J.-N. He, X. Huang, L. Zhang, L. Kong, K. Li, B. Peng, J. Am. Chem. Soc. 2017, 139, 4211-4217; b) F. Luo, Y. Lu, M. Hu, J. Tian, L. Zhang, W. Bao, C. Yan, X. Huang, Z.-X. Wang, B. Peng, Org. Chem. Front. 2018, 5, 1756-1762; c) L. Zhang, J.-N. He, Y. Liang, M. Hu, L. Shang, X. Huang, L. Kong, Z.-X. Wang, B. Peng, Angew. Chem. Int. Ed. 2019, in press; DOI: 10.1002/anie.201900434; Angew. Chem. 2019, in press; DOI: 10.1002/ange.201900434; Another example of interrupted Pummerer reaction of aryl sulfoxides with nitriles: d) B. Pégot, C. Urban, P. Diter, E. Magnier, Eur. J. Org. Chem. 2013, 7800-7808.

[7] Reviews: a) M. Vinicius, N. de Souza, J. Sulfur Chem. 2005, 26, 429449; b) S. J. Kashyap, V. K. Garg, P. K. Sharma, N. Kumar, R. Dudhe, J. K. Gupta, Med. Chem. Res. 2012, 21, 2123-2132; c) Z. Jin, Nat. Prd. Rep. 2013, 30, 869-915; d) A. Ayati, S. Emami, A. Asadipour, A. Shafiee, A. Foroumadi, Eur. J. Med. Chem. 2015, 97, 699-718; e) M. T. Chhabria, S. Patel, P. Modi, P. S. Brabmkshatriya, Curr. Top. Med. Chem. 2016, 16, 2841-2862.

[8] Reviews: a) A. Seed, Chem. Soc. Rev. 2007, 36, 2046-2069; b) Y. Yamashita, Chem. Lett. 2009, 38, 870-875; c) Y. Lin, H. Fan, Y. Li, X. Zhan, Adv. Mater. 2012, 24, 3087-3106.

[9] a) R. R. Gupta, M. Kumer, V. Gupta, in Heterocyclic Chemistry, Vol. 2, Springer, Heidelberg, 1999, 357-486; b) C. O. Kappe, A. Stadler, D. Dallinger, in Methods and Principles in Medicinal Chemistry, (Eds.: R. Mannhold, H. Kubinyi, G. Folkers), Wiley, Weinheim, 2012, 449-534; c) Preeti, K. N. Singh, Org. Biomol. Chem. 2018, 16, 9084-9116.

[10] Another method for the synthesis of thiazoles from nitriles, the reactions with a-mercaptocarbonyl compounds have been reported. a) F. Asinger, K. Fabian, H. Vossen, K. Hentshel, Liebigs Ann. Chem. 1975, 410-414; b) M. D. Broun, D. W. Gillon, G. D. Meakins, G. H. Whitham, J. Chem. Soc. Perkin Trans. 1 1985, 1623-1626.

[11] Selected recent reviews: a) S. Kobayashi, Chem. Asian J. 2016, 11, 425436; b) M. B. Plutschack, B. Pieber, K. Gilmore, P. H. Seeberger, Chem. Rev. 2017, 117, 11796-11893; c) B. Gutmann, C. O. Kappe, J. Flow. Chem. 2017, 7, 65-71; d) J. Yoshida, H. Kim, A. Nagaki, J. Flow Chem. 2017, 7, 60-64.

[12] T. Matsumura, T. Niwa, M. Nakada, Tetrahedron Lett. 2012, 53, 43134316.

[13] S. Otsuka, D. Fujino, K. Murakami, H. Yorimitsu, A. Osuka, Chem. Eur. J. 2014, 20, 13146-13149. 
WILEY-VCH

Entry for the Table of Contents (Please choose one layout)

\section{COMMUNICATION}

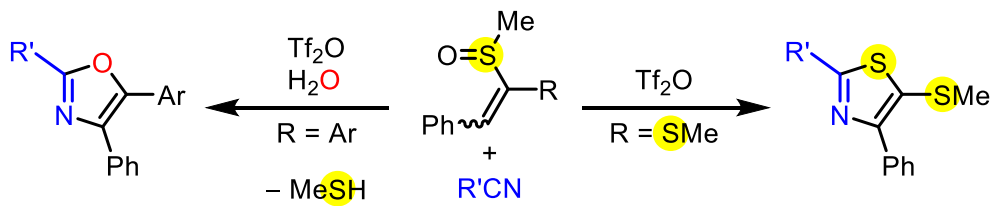

Pummerer-based annulation of alkenyl sulfoxides, mainly ketene dithioacetal monoxides (KDMs), with nitriles has been developed. Promoted by trifluoromethanesulfonic anhydride $\left(\mathrm{Tf}_{2} \mathrm{O}\right)$ as an activator, the corresponding thiazoles were obtained via additive Pummerer reaction and subsequent $\mathrm{C}-\mathrm{S}$-bondforming cyclization from the nitrilium intermediates. Moreover, the nitriliums proved to be interrupted intermolecularly by $\mathrm{H}_{2} \mathrm{O}$ to afford oxazoles instead of thiazoles.
M. Hori, K. Nogi, A. Nagaki, H. Yorimitsu*

Page No. - Page No.

Annulative Synthesis of Thiazoles and Oxazoles from Alkenyl Sulfoxides and Nitriles via Additive Pummerer Reaction 